\title{
Randomized controlled trial on the safety of intracameral cephalosporins in cataract surgery
}

This article was published in the following Dove Press journal:

Clinical Ophthalmology

8 December 2010

Number of times this article has been viewed

\section{Philip TH Lam \\ Alvin L Young \\ Lulu L Cheng \\ Patrick MK Tam \\ Vincent YW Lee}

Department of Ophthalmology and Visual Sciences, The Chinese University of Hong Kong, Prince of Wales Hospital, Shatin, Hong Kong SAR, China
Correspondence: Philip TH Lam Department of Ophthalmology and Visual Sciences, The Chinese University of Hong Kong, Prince of Wales Hospital, Shatin,

Hong Kong SAR, China

$\mathrm{Tel}+85226322879$

Fax +85226482943

Email pthlam@cuhk.edu.hk
Objective: To compare the safety profiles of intracameral cephalosporins in cataract surgery.

Patients and methods: In this controlled trial, 129 patients were randomized to one of four groups to receive $1 \mathrm{mg}$ of one of three cephalosporins - cefazolin, cefuroxime, or ceftazidime, or normal saline - given intracamerally during cataract surgery. Central endothelial cell density (ECD) and retinal center point thickness (CPT) were determined by specular microscopy and ocular coherence tomography, respectively, before and at 3 months after surgery.

Results: There were no statistical significant differences in the changes of ECD and CPT between eyes receiving intracameral cephalosporin and control.

Conclusion: The use of intracameral cefazolin, cefuroxime, or ceftazidime $(1 \mathrm{mg}$ in 0.1-mL solution) at the time of cataract surgery had no significant effect on ECD and CPT postoperatively.

Keywords: intracameral cephalosporin, endophthalmitis, phacoemulsification

\section{Introduction}

Postoperative endophthalmitis is a serious complication of cataract surgery that can lead to loss of sight or even loss of the eye. Peroperative topical application of $5 \%$ povidone-iodine or an antibiotic to the conjunctival sac was commonly used as prophylaxis against infection. ${ }^{1}$ Commensal bacteria could not be totally eliminated from the ocular surface and could contaminate the anterior chamber during cataract surgery. ${ }^{2-4}$ Peroperative intracameral application of antibiotics might eliminate bacteria that gained access to the anterior chamber. Antibiotics could be infused continuously during surgery along with the irrigating solution given either as a variable $\operatorname{dos}^{5}$ or as a fixed-dose bolus injection at the end of surgery. Cephalosporins and vancomycin were studied extensively in retrospective series and prospective trials providing evidence on clinical efficacy of intracameral cephalosporins. ${ }^{6-10}$ Safety aspects were studied via the effects on endothelial cell loss and macular thickening. Intracameral drug toxicity could lead to endothelial cell loss or diffuse into the posterior segment of the eye resulting in macular edema. In a nonrandomized trial, Montan et $\mathrm{al}^{11}$ showed the use of 1-mg intracameral cefuroxime did not lead to endothelial cell loss. Gupta et al ${ }^{12}$ also showed the same dose of intracameral cefuroxime did not lead to macular thickening. The effects of cefazolin and ceftazidime on endothelial cell loss and macular thickening were not reported in the European clinical studies. In this prospective randomized trial, we directly compared the safety profiles of three intracameral cephalosporins cefazolin, cefuroxime, and ceftazidime - given via the intracameral route. 


\section{Materials and methods}

This study was approved by the hospital clinical research ethics committee. Patients aged 50 years or above with senile cataract were recruited from the ophthalmic outpatient clinic of the hospital. Only one eye in a patient with bilateral cataract would be recruited into this study. At the recruitment visit, a comprehensive ocular examination was conducted, followed by optical biometry, and central endothelial density and central macular thickness measurements. These three measurements were conducted by trained technicians. Patients' steady fixation and cooperation were required for acquisition of reliable data. Patients giving a history of intraocular surgery or showing signs of ocular pathologies detected at the examination were excluded. Systemic conditions leading to exclusion were diabetes mellitus, uncontrolled hypertension, and heart or renal failure. Patients who would not consent to surgery under local or topical anesthesia were also excluded. Written informed consent to the study was obtained from those who satisfied inclusion criteria.

Central corneal endothelial cell density (ECD) was evaluated by fixed-frame analysis with a noncontact specular microscope (NonCon ROBO SP-8000; Konan Inc, Hoyogo, Japan). The area selected within each frame included 50 or more cells to qualify for manual analysis. Photographic evaluation of the cell image of the entire frame was also conducted. An ECD below 2000 cells $/ \mathrm{mm}^{2}$ or the presence of corneal guttata led to exclusion. Macular thickness was determined using time-domain optical coherence tomography (OCT). With the fast macular scan protocol provided with the Stratus OCT (Carl Zeiss Meditec, Dublin, CA), six equally spaced 6-mm radial scans each consisting of 100 sequential measurements were centered on the patient's fixation point. The software averaged the six scans to give the central area thickness. The center point thickness (CPT) was adopted as another primary outcome variable.

The sample size was calculated to have $80 \%$ power to detect a $5 \%$ significant difference of ECD or CPT between a cephalosporin and control. Patients were randomized to the operating lists of four participating surgeons. To control for variations, the randomization scheme was designed such that each surgeon would operate on around 32 eyes, about 8 eyes from each treatment group. Surgery was conducted within 14 days after the recruitment visit. Each surgeon used his or her most preferred lens removal and irrigation-aspiration technique, the same ophthalmic viscosurgical device, intraocular lens model, and lens delivery system to all eyes randomized to his or her surgical list. Intraocular lenses were to be implanted into the capsular bag. The use of a capsular stain or an intracameral miotic, posterior capsular break with or without vitreous presentation into the anterior chamber would lead to exclusion. To allow comparison of ultrasound energy used in the surgery, the effective phaco time (EPT) was calculated by multiplying the total phaco time by the average percentage power used. The EPT would be the phaco duration if $100 \%$ power continuous mode was used.

Three cephalosporins were compared - cefazolin (1-g vial; Chung Hwa, Suzhou, China), cefuroxime (750-mg vial, Zinacef $^{\circledR}$; GlaxoSmithKline, Brentford, UK), and ceftazidime (1-g vial, Fortum ${ }^{\circledR}$; GlaxoSmithKline). Solutions were prepared from the powder supplied in vials for intravenous use. The powder was first dissolved with normal saline (NS) $(0.9 \% \mathrm{NaCl}$; B Braun, Penang, Malaysia) to a concentration of $100 \mathrm{mg} / \mathrm{mL}$ in a $10-\mathrm{mL}$ syringe. The solution was further diluted to the concentration of $10 \mathrm{mg} / \mathrm{mL}$ with NS. Water for injection or balanced salt solution (BSS) was not used in the process. A hypotonic solution could result from dissolution and dilution with water for injection. Precipitations could form by mixing cephalosporin with BSS. Solutions were discarded $4 \mathrm{~h}$ after reconstitution.

The surgeons were supplied with a tuberculin syringe containing $1 \mathrm{mg}$ (in $0.1 \mathrm{~mL}$ ) of one of the three cephalosporins - cefazolin, cefuroxime, and ceftazidime drawn from the diluted drug in the $10-\mathrm{mL}$ syringe, or $0.1 \mathrm{~mL}$ of NS, which was to be injected into the anterior chamber at the end of surgery. The surgeons were masked as to which treatment was given until the surgery had been completed and patient had left the theater.

A standard topical antibiotic-steroid regime (dexamethasone and chloramphenicol) was commenced on the first postoperative day. Patients were seen again at 1 week, 1 month, and 3 months after operation by a masked observer. Central ECD and CPT were measured at 3 months ( \pm 2 weeks) postoperatively by the same trained technician masked to the treatment, previous specular microscopy, and OCT data.

The primary outcome variables were changes in ECD and CPT. Change in ECD was expressed as a percentage, obtained by dividing the difference between postoperative and preoperative values by the preoperative value. Similarly, the percentage change in CPT was obtained by dividing the difference between post- and preoperative thickness by the preoperative value. Using a statistical package (SAS version 9.1; SAS Institute, Cary, NC), the percentage changes in ECD and CPT with analysis of variance at an alpha value of 0.05 and the correlation between change in EPT and improvement of visual acuities were determined. Post hoc comparisons 
of the outcome variables with the Bonferroni $t$ tests among surgeons were also conducted.

\section{Results}

A total of 129 patients, comprising 49 males and 80 females, were recruited in this study. Mean age of the patients was 74.5 years ( $\mathrm{SD}=7$ years). They were randomized to be operated by one of the four participating surgeons. Details of their surgical preferences and the number of patients randomized are listed in Table 1. One patient in the cefuroxime group withdrew before the final follow-up visit. The four groups were comparable with regard to their mean age, biometry values, visual acuities, baseline ECD and CPT, and EPT (Table 2 ). The mean preoperative unaided visual acuity was $0.6( \pm 0.27) \log$ MAR. There was a mean improvement of 0.25 $( \pm 0.33) \log$ MAR after cataract surgery.

The mean pre- and postoperative ECD were $2546 \pm 334$ and $2286 \pm 463$ cells $/ \mathrm{mm}^{2}$, respectively. The mean change was $-9.9 \%( \pm 17.1 \%)$. The mean pre- and postoperative CPTs were $172 \pm 31$ and $179 \pm 40 \mu \mathrm{m}$. There was a small increase of foveal thickening at around $4.6 \%$. One patient in the cefazolin group developed clinical macular edema with a drop in visual acuity at the final visit. She required treatment with topical nonsteroidal anti-inflammatory agent.

We were unable to detect a statistically significant change in $\operatorname{ECD}(P=0.74)$ and $\mathrm{CPT}(P=0.36)$ between cephalosporins and control (Table 2). There was no significant correlation of changes in CPT and improvement in visual acuities after surgery (Pearson correlation $=0.07$, $P=0.43$ ). Post hoc analysis using the Bonferroni $t$ test showed the patients operated by one surgeon had a higher rate of endothelial cell loss $(P<0.0001)$ than the other three surgeons. This accounted for the larger standard deviation for postoperative endothelial density (463 cells $/ \mathrm{mm}^{2}$ ) compared with the preoperative value $\left(334\right.$ cells $\left./ \mathrm{mm}^{2}\right)$. No statistical difference was detected between the groups after patients operated by the surgeon were excluded from analysis.

\section{Discussion}

Effectiveness of intracameral cephalosporins as prophylaxis for postoperative endophthalmitis after cataract surgery was shown in large case series and randomized trials. Results from the European Society of Cataract and Refractive Surgeons (ESCRS) multicenter randomized control trial on 16,211 subjects showed the risk of endophthalmitis could be reduced by 4.9 -fold with an intracameral injection of cefuroxime. ${ }^{6}$ Another prospective study conducted in Spain involving 13,652 cataract patients concluded the efficacy of intracameral cefuroxime in reducing the risk of postoperative endophthalmitis. ${ }^{7}$ The choice of cefuroxime was based on the microbiological spectrum in the Swedish series of endophthalmitis cases from 1996 to $2000 .{ }^{10}$ In this series, 55 of 59 strains of pathogens isolated were sensitive to cefuroxime. Use of cefazolin was described in smaller retrospective case series from Spain. ${ }^{8,9}$ Cefazolin is a first-generation cephalosporin that has bactericidal effect against Gram-positive cocci, particularly staphylococci. Ceftazidime, a third-generation cephalosporin, was used in Sweden following an epidemic caused by a Gram-negative bacterium. ${ }^{10}$ Antibiotics chosen for prophylaxis were targeted toward either pathogens isolated

Table I List of participating surgeons' preferences on surgical methods, ophthalmic viscosurgical devices, intraocular lenses, implantation devices, and the number of eyes randomized to each surgeon

\begin{tabular}{|c|c|c|c|c|c|c|c|c|}
\hline \multirow[t]{2}{*}{ Surgeon } & \multirow{2}{*}{$\begin{array}{l}\text { Surgical } \\
\text { methods' }\end{array}$} & \multirow{2}{*}{$\begin{array}{l}\text { Ophthalmic } \\
\text { viscosurgical } \\
\text { devices }^{2}\end{array}$} & \multirow{2}{*}{$\begin{array}{l}\text { Intraocular lenses } \\
\text { and implantation } \\
\text { devices }^{3}\end{array}$} & \multicolumn{5}{|c|}{ Number of eyes } \\
\hline & & & & Cefazolin & Cefuroxime & Ceftazidime & $\begin{array}{l}\text { Normal } \\
\text { saline }\end{array}$ & Subtotal \\
\hline \multirow[t]{2}{*}{ A } & Stop and chop & Vitrax II and Healon & AcrySof SA60AT & 8 & 9 & 7 & 8 & 32 \\
\hline & Single coaxial I\&A & & Monarch C cartridge & & & & & \\
\hline \multirow[t]{2}{*}{ B } & Stop and chop & VisCoat and ProVisc & Tecnis Z9003 & 8 & $9^{4}$ & 9 & 7 & 33 \\
\hline & Bimanual I\&A & & Emerald C cartridge & & & & & \\
\hline \multirow[t]{2}{*}{ C } & Stop and chop & VisCoat and ProVisc & AcrySof SA60AT & 8 & 8 & 8 & 8 & 32 \\
\hline & Single coaxial I\&A & & Monarch C cartridge & & & & & \\
\hline \multirow[t]{3}{*}{ D } & Stop and chop & VisCoat and ProVisc & AcrySof SA60AT & 8 & 8 & 8 & 8 & 32 \\
\hline & Bimanual I\&A & & Monarch C cartridge & & & & & \\
\hline & & & Subtotal & 32 & 34 & 32 & 31 & 129 \\
\hline
\end{tabular}

Notes: 'Irrigating solution: To each $500-\mathrm{mL}$ bottle of balanced salt solution (Alcon Laboratories, Forth Worth, TX), $5 \mathrm{~mL}$ of I:I0,000 nonpreserved adrenaline acid tartrate (DBL, Mulgrave, Australia) was added; ${ }^{2}$ Vitrax II (sodium hyaluronate $30 \mathrm{mg} / \mathrm{mL}$ ), Healon (sodium hyaluronate $10 \mathrm{mg} / \mathrm{mL}$; Abbott Medical Optics, Santa Ana, CA), VisCoat (sodium hyaluronate $16.5 \mathrm{mg} / \mathrm{mL}$, sodium chrondoitin sulfate $40 \mathrm{mg} / \mathrm{mL}$ ), ProVisc (sodium hyaluronate $10 \mathrm{mg} / \mathrm{mL}$; Alcon Laboratories); ${ }^{3}$ AcrySof SA60AT one-piece intraocular lenses and Monarch delivery system (Alcon Laboratories), Tecnis Z9003 three-piece intraocular lenses and Emerald delivery system (Abbott Medical Optics); ${ }^{4}$ One patient in the cefuroxime group withdrew before the final visit. 
Table 2 Effects of intracameral cephalosporins versus normal saline (control) on endothelial cell density and central point thickness

\begin{tabular}{|c|c|c|c|c|c|}
\hline & Cefazolin & Cefuroxime & Ceftazidime & Normal saline & $P^{\prime}$ \\
\hline Number of eyes & 32 & $34^{2}$ & 32 & 31 & - \\
\hline \multicolumn{6}{|l|}{ Mean \pm SD } \\
\hline Age, years & $74.0 \pm 7.8$ & $73.9 \pm 7.4$ & $75.8 \pm 6.9$ & $74.2 \pm 6.1$ & 0.65 \\
\hline Axial length, mm & $23.70 \pm 0.98$ & $23.44 \pm 0.91$ & $23.42 \pm 0.70$ & $23.64 \pm 1.16$ & 0.55 \\
\hline Average keratometry, D & $44.13 \pm 1.55$ & $44.33 \pm 1.36$ & $44.04 \pm 1.28$ & $43.69 \pm 1.30$ & 0.31 \\
\hline \multicolumn{6}{|l|}{ Visual acuities, logMAR } \\
\hline Preoperative & $0.56 \pm 0.22$ & $0.63 \pm 0.28$ & $0.64 \pm 0.31$ & $0.56 \pm 0.25$ & 0.31 \\
\hline Change & $-0.15 \pm 0.28$ & $-0.31 \pm 0.35$ & $-0.31 \pm 0.30$ & $-0.21 \pm 0.36$ & 0.15 \\
\hline Effective phaco time, sec & $31.0 \pm 15.3$ & $28.1 \pm 19.2$ & $34.3 \pm 17.7$ & $26.7 \pm 15.6$ & 0.31 \\
\hline \multicolumn{6}{|c|}{ Endothelial cell density, cells $/ \mathrm{mm}^{2}$} \\
\hline Preoperative & $2555 \pm 349$ & $2567 \pm 327$ & $2536 \pm 385$ & $2528 \pm 280$ & 0.97 \\
\hline Postoperative & $2352 \pm 476$ & $2326 \pm 48 I$ & $2206 \pm 455$ & $2257 \pm 447$ & - \\
\hline Change, \% & $-7.7 \pm 18.0$ & $-9.0 \pm 17.0$ & $-12.0 \pm 18.0$ & $-11.0 \pm 15.7$ & 0.74 \\
\hline \multicolumn{6}{|c|}{ Central macular thickness, $\mu \mathrm{m}$} \\
\hline Preoperative & $171.9 \pm 23.8$ & $174.4 \pm 36.0$ & $172.1 \pm 32.4$ & $|7| .8 \pm 31.8$ & 0.99 \\
\hline Postoperative & $176.8 \pm 31.1$ & $178.7 \pm 51.5$ & $176.3 \pm 32.8$ & $187.1 \pm 45.7$ & - \\
\hline Change, \% & $2.9 \pm 10.7$ & $2.8 \pm 22.4$ & $3.3 \pm 13.0$ & $9.9 \pm 21.0$ & 0.32 \\
\hline
\end{tabular}

Notes: 'Analysis of variance, $P<0.05$ is considered statistically significant; ${ }^{2}$ One patient in the cefuroxime group withdrew before the final visit.

from cases of endophthalmitis ${ }^{10}$ or conjunctival cultures of patients undergoing cataract surgery. ${ }^{13}$ Methicillin-resistant staphylococci were resistant to cephalosporins, but not to vancomycin. Vancomycin was preferred by some groups for intracameral use after cataract surgery. ${ }^{14}$ The US Centers for Disease Control and Prevention cautioned against prophylactic use of vancomycin to reduce the risk of emergence of vancomycin-resistant organisms. ${ }^{15}$

Commercial preparations of cephalosporins for intracameral use had not been available. Solutions were reconstituted from the powder supplied for intravenous or intramuscular use. The manufacturers recommended the use of water for injection for reconstitution. ${ }^{16}$ For intracameral use, we used NS to reconstitute the solutions to avoid hypotonicity, as in the majority of clinical studies. ${ }^{9-11,17}$ In a study on the safety of intracameral cefuroxime, Gupta et $\mathrm{al}^{12}$ used BSS as control. We used NS as control in an attempt to differentiate the effect between cephalosporins, if such existed, and to avoid the confounding effect of a control that was different from the diluent. Risk of drug toxicity leading to toxic anterior segment syndrome could arise from dilution and dosing errors. Lockington et $\mathrm{al}^{17}$ compared two protocols for diluting cefuroxime and found errors could arise from using small (1.0-mL) syringes. The preparations used in this study were reconstituted from 1-g vials of cefazolin and ceftazidime and 750-mg vials of cefuroxime using 10-mL syringes, avoiding incomplete dissolution of drug powder and inaccuracies with small syringes. We discarded cephalosporin solutions $4 \mathrm{~h}$ after reconstitution to avoid possible loss of efficacy, despite the manufacturers confirmed compatibility with NS and retaining potency more than $12 \mathrm{~h}$ after reconstitution. ${ }^{16}$

In this study design, control for sources of variations was addressed. We excluded patients with long axial lengths (thin maculae) and any ocular or systemic conditions that could lead to postoperative macular edema. In clinical trials comparing effects of phacoemulsification methods or irrigating solutions on the cornea, variations arising from surgeons could be controlled by limiting the procedure to be conducted by a single surgeon. ${ }^{17,18}$ In this trial, four surgeons participated, and the number of eyes randomized to each treatment and control were closely matched for every surgeon, even though a perfect $4 \times 4$ allocation was not achieved. This design allowed the differentiation of treatment (drug) effect from the surgeon effect through statistical analysis. The mean endothelial cell loss of $9.9 \%$ in this study compared favorably with the results in two recent studies on endothelial cell loss in phacoemulsification. Using fortified BSS as irrigating solution, the mean cell loss at 2 months was $13.2 \%( \pm 2 \%)$ in Lucena's study ${ }^{19}$ and $22.9 \%( \pm 14 \%)$ at 3 months in the Richard et al study. ${ }^{20}$ In eyes operated by one participating surgeon, the mean cell loss was $19.8 \%$. This value was comparable to the mean cell loss by Richard et al. ${ }^{20}$

There was an inherent variability in the measurement of ECD. Variations could be reduced by cell analysis over a larger area or with repeated measurements. In practice, the area of endothelial cells available for counting was limited by magnification and the area brought under focus of the specular microscope. In this study, 50 or more endothelial cells 
per frame were accepted for analysis. We did not compare the absolute cell loss as Montan et $\mathrm{al}^{10} \mathrm{did}$ in their study on the safety of intracameral cefuroxime. Anticipating a wide range of preoperative cell densities (ranging from 2005 to 3683 cells $/ \mathrm{mm}^{2}$ ), we analyzed the percentage changes rather than the absolute differences between the pre- and postoperative ECD values. The percentage values could convey the magnitude of cell loss with regard to the baseline ECD. We measured ECD at one single time point, namely at 3 months, postoperatively. In a study comparing corneal changes after phacoemulsification using fortified BSS versus lactated Ringer's solution, Lucena et $\mathrm{al}^{19}$ observed endothelial cell count stabilized after 2 weeks postoperatively. It was less likely that the drugs could cause continual endothelial cell loss, and these effects could be picked up if the measurements were conducted at a later date.

To study the effect on macular thickness, we used CPT as our primary outcome variable similar to the study by Kim et al. ${ }^{21}$ No topical nonsteroid anti-inflammatory agent was used in the pre- and immediate postoperative stage. This could have masked the difference in change of macular thickness, if any, between the groups. We were unable to detect any statistical difference in CPT between treatment and control groups. Our result showed a mean increase of $4.6 \%$ (or $7.0 \mu \mathrm{m}$ ) in CPT in the postoperative period. This value concurred with other OCT studies on changes of retinal thickness with cataract surgery using Stratus OCT. Kurz's group demonstrated a $6-8-\mu \mathrm{m}$ increase in CPT at 8 weeks after microincisional cataract surgery. ${ }^{22}$ Kim et al showed a mean 9- $\mu \mathrm{m}$ increase in CPT at 12 weeks. ${ }^{21}$ Biró et al advocated using the $6-\mathrm{mm}$ perifoveal retinal thickness for a more sensitive measure for detecting macular edema. $^{23,24}$ They showed $5.3 \%$ increase in $6-\mathrm{mm}$ perifoveal values at 2 months after phacoemulsification. The increase was maximal at 1 month and had not resolved at 6 months postoperatively.

\section{Conclusion}

This study could not detect any statistical difference in changes in ECD or CPT between cephalosporins and control. The magnitude of endothelial cell loss and macular thickening detected in this study was not in excess of that after uneventful cataract surgery, and thus it could not be ascribed to the use of any one of the three intracameral cephalosporins. Cefazolin, cefuroxime, and ceftazidime could be considered safe for intracameral use when $1 \mathrm{mg}$ in $0.1 \mathrm{~mL}$ was given during cataract surgery.

\section{Disclosure}

The authors report no conflicts of interest in this work.

\section{References}

1. Ciulla TA, Starr MB, Masket S. Bacterial endophthalmitis prophylaxis for cataract surgery: an evidence-based update. Ophthalmology. 2002;109(1):13-24.

2. Mistlberger A, Ruckhofer J, Raithel E, et al. Anterior chamber contamination during cataract surgery with intraocular lens implantation. J Cataract Refract Surg. 1997;23(7):1064-1069.

3. Tervo T, Ljungberg P, Kautiainen T, et al. Prospective evaluation of external ocular microbial growth and aqueous humor contamination during cataract surgery. J Cataract Refract Surg. 1999;25(1):65-71.

4. John T, Sims M, Hoffmann C. Intraocular bacterial contamination during sutureless, small incision, single-port phacoemulsification. J Cataract Refract Surg. 2000;26(12):1786-1791.

5. Sobaci G, Tuncer K, Taş A, Özyurt M, Bayer A, Kutlu U. The effect of intraoperative antibiotics in irrigating solutions on aqueous humor contamination and endophthalmitis after phacoemulsification surgery. Eur J Ophthalmol. 2003;13(9-10):773-778.

6. Endophthalmitis Study Group, European Society of Cataract and Refractive Surgeons. Prophylaxis of postoperative endophthalmitis following cataract surgery: results of the ESCRS multicenter study and identification of risk factors. J Cataract Refract Surg. 2007;33(6): 978-988.

7. García-Sáenz MC, Arias-Puente A, Rodrígeuz-Caravaca G, Bañuelos JB Effectiveness of intracameral cefuroxime in preventing endophthalmitis after cataract surgery: ten-year comparative study. J Cataract Refract Surg. 2010;36(2):203-207.

8. Garat M, Moser CL, Alonso-Tarrés C, Martín-Baranera M, Alberdi A. Intracameral cefazolin to prevent endophthalmitis in cataract surgery: 3-year retrospective study. J Cataract Refract Surg. 2005;31(11): 2230-2233.

9. Romero P, Méndez I, Salvat M, Fernández J, Almena M. Intracameral cefazolin as prophylaxis against endophthalmitis in cataract surgery. $J$ Cataract Refract Surg. 2006;32(3):438-441.

10. Montan PG, Wejde G, Koranyi G, Rylander M. Prophylactic intracameral cefuroxime. Efficacy in preventing endophthalmitis after cataract surgery. J Cataract Refract Surg. 2002;28(6):977-981.

11. Montan PG, Wejde G, Setterquist H, Rylander M, Zetterström C. Prophylactic intracameral cefuroxime. Evaluation of safety and kinetics in cataract surgery. J Cataract Refract Surg. 2002;28(6):982-987.

12. Gupta MS, McKee HDR, Saldaña M, Stewart OG. Macular thickness after cataract surgery with intracameral cefuroxime. J Cataract Refract Surg. 2005;31(6):1163-1166.

13. Fernández-Rubio E, Urcelay JL, Cuesta-Rodrigeuz T. The antibiotic resistance pattern of conjunctival bacteria: a key for designing a cataract surgery prophylaxis. Eye (Lond). 2009;23(6):1321-1328.

14. Anijeet DR, Palmar P, Peckar CO. Intracameral vancomycin following cataract surgery: an eleven-year study. Clin Ophthalmol. 2010;4: 321-326.

15. Hospital Infection Control Practices Advisory Committee (HICPAC). Recommendations for preventing the spread of vancomycin resistance. Infect Control Hosp Epidemiol. 1995;16(2):105-113. Erratum in Infect Control Hosp Epidemiol. 1995;16(9):498.

16. Electronic Medicines Compendium (eMC). Zinacef, Fortum. Summary of product characteristics (SPC). Datapharm Communications Ltd. 2010. Available from: http://www.medicines.org.uk/EMC/medicine/781/SPC/ Zinacef/ and http://www.medicines.org.uk/EMC/medicine/19176/SPC/ Fortum+1g+Injection. Accessed Oct 102010.

17. Lockington D, Flowers H, Young D, Yorston D. Assessing the accuracy of intracameral antibiotic preparation for use in cataract surgery. $J$ Cataract Refract Surg. 2010;36(2):286-289.

18. Fine IH, Packer M, Hoffman RS. Use of power modulations in phacoemulsification. Choo-choo chop and flip phacoemulsification. J Cataract Refract Surg. 2001;27(2):188-197. 
19. Lucena DR, Ribeiro MS, Messias A, Bicas HE, Scott IU, Jorge R. Comparison of corneal changes after phacoemulsification using BSS Plus versus lactated Ringer's irrigating solution: a prospective randomised trial. Br J Ophthalmol. 2010. [Epub ahead of print].

20. Richard J, Hoffart L, Chavane F, Ridings B, Conrath J. Corneal endothelial cell loss after cataract extraction by using ultrasound phacoemulsification versus a fluid-based system. Cornea. 2008;27(1):17-21.

21. Kim SJ, Belair ML, Bressler NM, et al. A method of reporting macular edema after cataract surgery using optical coherence tomography. Retina. 2008;28(6):870-876.
22. Kurz S, Krummenauer F, Thieme H, Dick HB. Optical coherence tomography of macular thickness after biaxial vs coaxial microincision clear corneal cataract surgery. Eur J Ophthalmol. 2009;19(6): 990-997.

23. Biró Z, Balla Z, Kovacs B. Change of foveal and perifoveal thickness measured by OCT after phacoemusification and IOL implantation. Eye (Lond). 2008;22(1):8-12.

24. Biró Z, Balla Z. OCT measurements on the foveal and perifoveal retinal thickness on diabetic patients after phacoemulsification and IOL implantation. Eye (Lond). 2010;24(4):639-647.
Clinical Ophthalmology

\section{Publish your work in this journal}

Clinical Ophthalmology is an international, peer-reviewed journal covering all subspecialties within ophthalmology. Key topics include: Optometry; Visual science; Pharmacology and drug therapy in eye diseases; Basic Sciences; Primary and Secondary eye care; Patient Safety and Quality of Care Improvements. This journal is indexed on

\section{Dovepress}

PubMed Central and CAS, and is the official journal of The Society of Clinical Ophthalmology (SCO). The manuscript management system is completely online and includes a very quick and fair peer-review system, which is all easy to use. Visit http://www.dovepress.com/ testimonials.php to read real quotes from published authors. 